\title{
ANALISIS ANDROGINI PADA NOVEL "AMELIA" KARYA TERE-LIYE
}

\author{
Oleh \\ Fheti Wulandari Lubis \\ Emai: wulanlubis119@gmail.com
}

(Dosen Pend. Bahasa dan Sastra Indonesia STKIP Budi Daya Binjai)

Adrogini merupakan gambaran sifat maupun perilaku yang menunjukkan pembagian peran yang sama dalam karakter maskulin dan feminism pada saat yang bersamaan. Karakterdan kepribadian seseorang tidah hanya muncul dari lahir, tetapi bisa dibentuk oleh lingkungan tempat tinggalnya. Oleh karena itu, penelitian ini bertujuan untuk mendeskripsikan gambaran androgini pada novel "Amelia" karya Tere- Liye. Androgini dalam novel yang menjadi objek dalam penelitian ini. Peneliti menggunakan metode kualitatif dengan teknik kajian pustaka. Hasilnya, terdapat peran feminim dan maskulin secara bersamaan dalam novel "Amelia" karya Tere- Liye. Di mana seorang wanita bisa melakukan peran sebagai wanita dalam keadaan secara tiba-tiba.

Kata kunci : Androgini, Novel "Amelia” karya Tere-Liye

\section{PENDAHULUAN}

Manusia diciptakan laki-laki dan wanita untuk saling berpasangan. Dengan sifat dan karakter yang berbeda satu dengan yang lain. Serta dengan tugas dan kewajiban masingmasing. Sehingga cara menghadapi suatu masalah laki-laki dan perempuan pasti berbeda. Biasanya sebahagian besar laki-laki menghadapi masalah dengan egois, tempramen, spontanitas. Sedangkan sebahagian wanita menghadapi suatu masalah dengan santai, lembut, bahkan sering memendam amarahnya.

Keanggunan, kelembutan, dan kesabaran yang dimiliki seorang wanita sangat berperan dalam pembentukan karakter. Wanita lebih bersifat feminim sehingga menimbulkan kasihsayang dariseorang wanita tersebut. Sedangkan seorang laki-laki harus bersifat maskulin yang beridentik tegas dan agresif. Sehingga secara umum masyarakat perpandangan bahwasannya seorang laki-laki harus bekerja mencari uang di luar rumah. Sedangkan wanita hanya di rumah saja.
Berdasarkan pendapat Jhin $\mathrm{M}$. Ivancevich (2006:103) menyatakan bahwa ciriciri feminim dan maskulin dalam diri seorang laki-laki dan perempuan. Laki-laki lebih maskulin yaitu laki-laki yakin akan diri sendiri, agresif, kompetetif, pengambik keputusan. Sedangkan wanita lebih feminim yaitu lebih simpatik, lembut, pemalu, sensitif terhadap apapun.

Selain penjelasan di atas kajian androgini telah dibahas oleh beberapa peneliti sebelumnya. Hasil penelitian yang dilakukan oleh nurul dan Sri (2010:136) menyimpulkan terdapatnya hubungan yang signifikan antara persepsi terhadap peran jenis androgini dengan pencapaian status identitas diri achievement mahasiswa. Hasil penelitian tersebut berlawanan dengan hasil penelitian yang dilakukan oleh Amriel, dkk (2007:3). Dalam penelitiannya, semangkin tinggi konflik antara keluarga pekerja, maka akan semakin rendah kepuasan kerja yang dipersepsi oleh para karyawati ataupun sebaliknya.

Oleh karena itu penulis membuat penelitian androgini yang dilihat dari dalam novel "Amelia" karya Tere-Liye. Dimana 
novel ini salah satu bentuk karya sastra prosa. Sastra merupakan sebuah ciptaan dan kreasi dari akal pikiran manusia. Sastra merupakan salah satu bentuk dan bukti kebudayaan umat manusia. Secara etimologis, sastra berarti buku, tulisan atau huruf. Kosasih (2008:194) memaparkan bahwa sastra merupakan suatu tulisan atau karangan yang mengandung nilai nilai kebaikan yang ditulis dalam bahasa yang indah. Selanjutnya, Luxemburg dkk (1989:5) mengemukakan bahwa sastra merupakan sebuah ciptaan, kreasi yang bersifat otonom serta komunikatif.

Novel adalah salah satu jenis karya sastra prosa yang memiliki jalinan cerita yang kompleks. Kekompleksan dalam novel sering ditunjukkan dengan adanya konflik yang tidak hanya sekali muncul dalam novel. Selain itu, kekompleksan cerita dalam novel juga terlihat pada keterkaitan antara unsur - unsur dalam novel itu sendiri. Selain itu, karya sastra berbentuk novel selalu berusaha menyampaikan nilai - nilai tertentu dalam rangkaian cerita yang dibuat oleh pengarangnya

Berdasarkan pemaparan di atas, penulis tertarik untuk melakukan penelitian mengenai Androgini terdapat dalam sebuah karya sastra berupa novel. Maka peneliti menetapkan judul penelitian ini adalah "Analisis Androgini pada Novel 'Amelia' Karya Tere-Liye.”

\section{Androgini}

Androgini adalah istilah yang digunakan untuk menunjukkan pembagian peran yang sama dalam karakter maskulin dan feminim pada saat yang bersamaan. Istilah ini berasal dari dua kata dalam bahasa Yunani yaitu avrip (aner yang berarti laki-laki) dan yuvn (gune yang berarti perempuan). Sadli (2005:95) menyatakan bahwa androgini adalah seseorang yang memiliki karakteristik psikologi feminim dan maskulin (andro = lakilaki, dan gyn = perempuan). Gambaran ini sering disebut sebagai stereopit gender. Pengembangannya berupa seksualitas yang tidak dibatasi oleh perilaku tentang gender sehingga memberikan kebebasan memiliki ciriciri yang dimiliki gender lain.
Selain itu dalam bukunya, Handayani 92004:161) menyatakan bahwa apa yang diharapkan, ditentukanatau dilarang bagi jenis kelamin tertentu digunakan untuk menguraikan aspek antropologis, soaiologis, dan kultural dari peranan maskulin dan feminim. Sejalan dengan pendapat di atas Akbar dan Hawadi 92004:69) menyatakan bahwa ciri-ciri androgini yaitu (1) dapat bertingkah laku feminimatau seoerti ekspresif, lembut, sensitif, hangat, dan penuh pengertian. (2) dapat bertingkah laku maskulin, seperti mandiri, tegas, dan agresif.

Dari uraian di atas, dapat disimpulkan androgini adalah kemampuan untuk mengadopsi karakteristik feminin dan maskulin secara bersamaan dalam taraf yang sama-sama setara agar dapat mendukung keluwesannya dalam menghadapi masalah yang negatif..

\section{Novel}

Salah satu bentuk karya sastra adalah novel. Istilah novel berasal dari bahasa Italia yaitu novella yang berarti sebuah barang baru yang yang kecil. Kosasih ( 2008 : 223 ) menyatakan bahwa novel adalah karya imajinatif yang mengisahkan sisi utuh atas problematika kehidupan seseorang atau beberapa orang tokoh. Kisah dalam novel berawal dari kemunculan suatu persoalan yang dialami tokoh hingga tahap penyelesaiannya. Selanjutnya Tim Penyusun Kamus Pusat Bahasa ( 2007 : 788) menjelaskan bahwa novel merupakan karangan prosa yang panjang yang mengandung rangkaian cerita kehidupan seseorang dengan orang di sekelilingnya dengan menonjolkan watak dan sifat setiap pelaku.

Novel adalah salah satu jenis karya sastra prosa yang memiliki jalinan cerita yang kompleks. Kekompleksan cerita dalam novel sering ditunjukkan dengan adanya konflik yang tidak hanya sekali muncul dalam novel. Tingkat kedalaman dan keluasan cerita inilah yang menjadikan novel berbeda dengan cerpen dan roman.

Badudu dan Zain (1994 : 949) memaparkan bahwa novel merupakan karangan dalam bentuk prosa tentang peristiwa yang berhubungan dengan kehidupan manusia 
seperti yang dialami dalam kehidupan sehari hari, tentang suka duka, kasih dan benci, tentang watak dan jiwanya, dan sebagainya.

Nurgiyantoro (2000 : 81) menjelaskan bahwa novel terbagi dua yaitu novel populer dan novel serius. Novel populer lebih bersifat menghibur, komersil, mudah dinikmati. Sedangkan novel serius yang dikenal sebagai novel sastra membutuhkan keseriusan saat membacanya agar dapat memahami keseluruhan isi cerita pada novel tersebut.

Seorang novelis membutuhkan pengetahuan yang luas untuk terjun ke dunia sastra. Hal ini dikarenakan, seorang novelis akan menciptakan sebuah dunia baru dan menjadi sutradara yang mengatur perjalanan para tokoh di novelnya. Jika novelis bertindak asal - asalan saja dalam membuat novelnya, maka novelnya tidak akan mendapat tempat yang layak di hati masyarakat .

Siswanto (2008 : 58) mengemukakan bahwa apa yang disampaikan pengarang tidak bisa dilepaskan dari apa yang telah diinderanya. Bahkan setiap pengarang atau sastrawan seringkali melakukan berbagai bentuk pendekatan dengan alam dan lingkungan sosial demi mendapatkan ide sebagai bahan mentah karya yang akan diciptakannya.

Berdasarkan pemaparan di atas, maka dapat disimpulkan bahwa novel merupakan karya sastra berbentuk prosa yang mengisahkan suatu problematika kehidupan seseorang ataupun beberapa orang tokoh, baik yang berdasarkan kenyataan ataupun hanya imajinasi si pengarang novel. Novel memiliki tema cerita yang kompleks, karakter tokoh yang banyak, alur cerita yang lebih rumit dan panjang serta latar dan suasana cerita yang beragam . Novel yang berkualitas selalu berupaya menyajikan hiburan dan nilai - nilai kehidupan secara seimbang melalui rangkaian peristiwa yang membentuk alur cerita dalam novel tersebut.

\section{Unsur Pembangun Novel}

Novel memiliki unsur pembangun yang sama dengan karya sastra berbentuk prosa lainnya seperti cerpen, dongeng, maupun roman. Unsur pembangun novel meliputi dua unsur yaitu unsur intrinsik dan unsur ekstrinsik.
Unsur intrinsik merupakan unsur yang terdapat di dalam karya sastra tersebut. Sedangkan unsur ekstrinsik merupakan unsur yang terletak di luar karya sastra dan hanya bersifat mendukung ataupun mempengaruhi isi suatu karya sastra. Somad (2010: 53 ) memaparkan bahwa unsur ekstrinsik meliputi latar belakang penciptaan, sejarah, biografi pengarang dan hal lainnya yang turut melengkapi sebuah bangunan cerita. Perhatian terhadap unsur ekstrinsik akan membantu keakuratan penafsiran isi suatu karya sastra. Unsur intrinsik novel meliputi tema, alur, latar, penokohan, sudut pandang pengarang, amanat dan gaya bahasa.

Adapun penjelasan mengenai unsur intrinsik novel tersebut adalah sebagai berikut : 1. Tema

Tema merupakan ide dasar yang menjadi inti atay gagasan pokok yang dikemukakan penyair.

2. Alur (Plot)

Alur adalah rangkaian peristiwa yang membentuk jalan cerita .

3. Latar (Setting)

Latar merupakan gambaran waktu, tempat dan suasana..

4. Penokohan

Penokohan merupakan bagian unsur intrinsik yang meliputi tokoh - tokoh dalam cerita dan karakternya.

5. Sudut Pandang Pengarang (Point of View)

Sudut pandang adalah cara pengarang memposisikan dirinya dalam bercerita.

6. Amanat

Amanat merupakan pesan yang disampaikan pengarang di dalam karya sastranya.

7. Gaya Bahasa

Penggunaan bahasa dalam karya sastra berfungsi untuk menciptakan suatu nada dan suasana.

\section{Sinopsis Novel "Amelia" Karya Tere-} Liye

'Inilah kisah Amelia, si bungsu dari empat anak-anak Mamak. Anak yang paling teguh hatinya, yang paling kuat pemahaman baiknya. Novel ini, seperti tiga buku sebelumnya yang menceritakan kisah kakak- 
kakaknya (Eliana, Pukat, dan Burlian), menceritakan hari-hari Amelia, anak bungsu dari keluarga Syahdan. Amelia yang benci dirinya terlahir sebagai anak bungsu, yang menurutnya membuat dirinya disuruh-suruh kakak sulungnya, Eliana, juga diledek dua kakak laki-lakinya, Pukat dan Burlian. Hingga pada puncak kekesalannya, Amelia mengerjai kakaknya, Eliana, hingga ia marah besar. Sekalipun Bapak malam itu langsung mengajaknya bicara, sampai saat itu Amel masih belum mengerti, di mana letak kasih sayang Kak Eli pada dirinya.

Amelia yang memiliki teman dengan nama paling aneh sekecamatan, Chuck Norris, biang ribut sekolah yang sering membuat masalah. Tapi entah mengapa Pak Bin, satu-satunya guru di sekolahnya malah memintanya untuk membantu Norris belajar. Amelia mencoba bersabar menghadapi kenakalan temannya itu. Sampai suatu ketika, ia mengetahui masa lalu Norris. Sejatinya, Norrris tidak nakal. Ia hanya tumbuh dengan segala pemberontakan masa kanak-kanak.

Amelia merupakan anak yang tidak mau dibedakan dengan kakaknya. Amelia yang tidak mau menjadi 'penunggu rumah'. Hal yang pada saat itu merupakan tradisi kampungnya. Anak bungsu adalah 'penunggu rumah', tidak kemanamana. Menjaga orang tua serta rumah dan lading di kampung saja. Tidak pergi jauh ke pelosok dunia. Tidak bisa jadi apa-apa. Walaupun saat ini ia masih belum mengetahui apa cita-citanya. Amelia sungguh ingin melihat dunia luas serta melakukan hal-hal hebat. Dan ia sungguh takut jika kelak ia akan benar-benar hanya menjadi 'penunggu rumah'.

Di dalam kelasnya Amelia selalu memahami penjelasan Pak Bin di kelas tentang bibit tanaman baik yang akan menumbuhkan tanaman baik. Yang hasil panennya dapat mencapai tiga sampai empat kali lipat hasil panen penduduk kampung sekarang. Ia ingin sekali penduduk kampung lebih sejahtera jika menggunakan bibit-bibit terbaik pada ladangnya. Tidak terus-terusan bertani dengan cara-cara lama para leluhur, melainkan menggunakan cara-cara yang berdasar pada ilmu pengetahuan. Namun Amelia juga sadar, mengubah cara bertani penduduk tidak akan mudah. Amelia terus berusaha sekuat tenaga agar mimpinya itu dapat tercapai.

Amelia juga menemukan bibit unggul. Dia bersama warga dikampung tempat tinggalnya mulai menanam bibit kopi unggul tersebut. Tetapi sangat disayangkan usaha yang dibuatnya bersama dengan warga kampung mengalami kegagalan. Walaupun mengalami kegagalan tetapi warga tidak menyalahkanya karena kesalahan bukan berasal dari Amelia tetapi karena alam. Hal ini membuat Amelia kecewa dan marah dengan dirinya sendiri. Tetapi dia tidak mau merasa terpuruk dengan kejadian itu, dia langsung bangkit menghadapi hari.

\section{METODOLOGI PENELITIAN}

Penelitian ini menggunakan pendekatan kualitatif dengan metode deskriptif analisis. Untuk mengumpulkan data, peneliti menggunakan kajian pustaka dengan cara membaca dan menganalisis dan memahami secara konseptual berupaya menemukan, mengidentifikasi, mengolah dan menganalisis dokumen untuk memahami makna, signifikasi dan relevansinya. Menganalisis data dalam penelitian ini dilakukan dengan cara menguasai unsur - unsur novel, Peneliti akan membaca dan menganalisis data secara berulang - ulang agar interpretasi data penelitian lebih terpercaya dan dapat dipertanggungjawabkan keabsahannya. Selanjutnya hasil analisis data penelitian tersebut disesuaikan dengan pendapat ahli yang berkaitan dengan masalah dalam penelitian.

\section{III.PRILAKU ANDROGINI PADA NOVEL "AMELIA" KARYA TERE-LIYE}

\begin{tabular}{|l|l|}
\hline PRILAK & HALAMAN \\
U & \\
ANDRO & \\
GINI & \\
\hline 1. Perilaku & Halaman \\
\hline
\end{tabular}




\begin{tabular}{|l|l|}
\hline yang & $6,7,13,14,28,35,39,50,51,64$ \\
dilakuk & $, 71,73$ \\
an & $79,125,185,241,272,293,30$ \\
seorang & $7,318,321$ \\
anak & 327, \\
lelaki & \\
yang & \\
mengerj & \\
akan & Halaman \\
pekerjaa & $23,24,26,56,57,59,123,132$, \\
n anak & 174,180 \\
peremp & $182,310,325,328,339,388$ \\
uan dan & \\
pekerjaa & Halaman \\
n & $20,61,82,137,145,146,186,2$ \\
wanita & $57,356,371$, \\
dewasa & 372 \\
dan & \\
sebalikn & Halaman $, 15,17,43,59,97$, \\
ya & 341,374, \\
& \\
2. Prilaku & \\
seorang & \\
bapak & \\
yang & \\
lembut & \\
4erilaku & \\
seorang & \\
kakak & \\
yang & \\
tegas & \\
seorang & \\
ibu & \\
yang & \\
tegas & \\
& \\
\hline
\end{tabular}

Berdasarkan uraian androgini yang terdapat pada novel " Amelia " karya Tere-Liye di atas, maka jelaslah bahwa novel tersebut memiliki keterangan tentang androgini yang dapat kita jadikan teladan.

\section{PENUTUP}

Pembagian androgini yang beragam. Pembagian ini dapat dilihat dari percakapan dan sikap para tokoh kepada tokoh lain. Novel "Amelia " karya Tere-Liye memiliki hubungan yang sangat harmonis dengan orang tua, kakak, teman, dan guru. Novel ini bisa dijadikan contoh untuk menimbulkan dan meningkatkan kasih sayang dalam keuarga. Selain itu novel ini merupakan salah satu novel serial anakanak mamak. Berdasarkan hasil analisis data dan pembahasan dalam penelitian ini yang telah dijabarkan pada bab sebelumnya, Novel yang diteliti mengandung androgini. Maka novel ini bisa dijadikan pilihan pembaca dari kalangan apa saja untuk mengetahui bahwasannya membawa pandangan positif bagi keseimbangan mental dan pola pikir.

Hadirnya karakter feminim-maskulin membuka peluang kesetaraan gender, hingga tidak menutup diri pada pendidikan, pergaulan, pejerjaan, dan potensi untuk lebih baik. Oleh karena itu masyarakat di era modernisasi ini wajib memiliki karakter feminim-maskulin yang sama besar seperti yang ada dalam novel ini.

\section{DAFTAR PUSTAKA}

Amriel, dkk. 2007.Hubungan Konflik Peran

Ganda dengan Perilaku Agresif pada

Wanita Karier. Universitas

Muhammadiyah Surakarta. Vol. 9. No.

2 November 2007.

Arikunto, Suharsimi. 2006. Prosedur

Penelitian. Jakarta: Rineka Cipta.

Aziez, Furkqonul dan Abdul Hasim. 2010. Analisis Fiksi. Jakarta : Multi KreasiSatudelapan. 
Bungin, Burhan. 2011. Metodologi Penelitian Aktualisasi Metodologis ke Arah Ragam Varian Kontemporer. Jakarta: Rajawali Pers.

Panjaitan, Chery Julida. 2017. Etnopsikologi: Androgini dalam Masyarakat Aceh. Seminar Nasional Dies Natalis Ke-27 STKIP Budidaya Binjai, Binjai: 2 November 2017. Hal. 231-245.

Endraswara, Suwardi. 2008. Metodologi Penelitian Sastra Epistemologi, Model, Teori, dan Aplikasi. Yogyakarta: Media Pressindo.

Faruk. 2003. Sosiologi Sastra. Yogyakarta : Pustaka Pelajar.

Haryanta, Agunf Tri. 2012. Kamus Kebahasaan dan Kesusastraan. Surakarta:Aksara Sinergi.

Kosasih, E. 2004. Ketatabahasaan dan Kesusasteraan. Bandung : Yrama Widya. Liye, Tere.2013. Amelia. Jakarta: Republika.

Martono, Nanang. 2011. Metode Penelitian Kuantitatif Analisis Isi dan Analisis Data Sekunder. Jakarta: Rajawali Pers.

Moleong, Lexy J. 2010. Metodologi Penelitian Kuantitatif. Bandung : Remaja Rosdakarya.

Nurapni, Popi. 2010. Ragam Sastra Indonesia. Jakarta : Sketsa Aksara Lalitya.

Nurgiyantoro, Burhan. 2000. Teori Pengkajian Fiksi. Yogyakarta : Gadjah Mada University Press.

Pradopo, Rachmat Djoko dkk. 2003. Metodologi Penelitian Sastra. Yogyakarta : Hanindita.

Purba, Antilan. 2008. Sastra Bangsa Indonesia. Medan : USU Press.

Riduwan. 2009. Metode dan Teknik Menyusun Tesis. Bandung : Alfabeta.
Sari. Laela dan Nurlailah. 2008. Kamus Istilah Sastra, Cetakan ke 2.Bandung: Nuansa Aulia.

Setyosari, Punaji. 2010. Metode Penelitian Pendidikan dan Pengembangan. Jakarta : Kencana.

Siswanto, Wahyudi. 2008. Pengantar Teori Sastra. Jakarta: Grasindo.

Somad, Adi Abdul. 2010. Mengenal Berbagai Karya Sastra. Bekasi : Adhi Aksara Abadi Indonesia.

Sugiyono. 2010. Metode Penelitian Kuantitatif dan $R d D$. Bandung : Alfebeta.

Tim Penyusun Kamus Pusat Bahasa. 2008. Kamus Besar Bahasa Indonesia Cetakan ke 4. Jakarta: Balai Pustaka.

Tim Widya Gamma. 2000. Sari Materi Penting Bahasa Indonesia. Bandung : Yrama Widya.

Yudiono. 2009. Pengkajian Kritik Sastra Indonesia. Jakarta: Gramedia. 